\title{
EDITORIAL
}

\section{Military Surgery, Past, Present and Future}

MiLITARY surgery comprises the whole range of surgery with emphasis on trauma and missile wounds. Throughout the ages, it has both reflected contemporary surgical standards and contributed to developments in surgery. In this issue Lieutenant General Sir Robert Drew's 1966 Hunterian Oration gives a fascinating account of the career of John Hunter (1728-1793) as a Staff Surgeon on active service and, later in life, as Surgeon General. It was not until a year after his death that his treatise on gunshot wounds was published: his wound surgery was essentially conservative following the principles expounded some two centuries earlier by Ambroise Paré (1509-1590) namely, to delay amputation and other surgical measures until inflammation had subsided. Before Hunter's lifetime, however, Wiseman (1623-1676) had advised early surgery, and a French contemporary of Hunter's, Desault (1744-1795), practised debridement (wound incision) and excision of dead tissue. It was Desault's brilliant pupil, and Napoleon's principal medical officer, Larrey (1766-1842) who realised the importance of wound excision before inflammation set in and its urgency by speeding up evacuation of wounded using a system of "flying ambulances" organised by Percy (1754-1825). In the Peninsular War G. J. Guthrie (1785-1856) also did immediate amputations and early wound surgery with beneficial results.

In the 19th Century the introduction of anaesthetics, antiseptics and later x-rays gave a tremendous spurt to surgery: and before these a significant step forward had been taken in military surgery: public concern about the care of wounded in the field and the need of instruction in the management of wounds led to the establishment of a chair of military surgery at Edinburgh in 1806. The chair lapsed in 1855 and in 1860 an Army chair of Military Surgery was instituted and is still in existence. In 1963, it became a Joint Chair between the Royal Army Medical College and the Royal College of Surgeons of England.

In the 20th Century, the gigantic casualty rate of the 1914-18 War and the appalling incidence of wound infection, particularly of a clostridial nature, led to vigorous developments in antiseptics and antisera, to the Carrel-Dakin technique of wound irrigation with sodium hypochlorite, and later to Winnet Orr's closed plaster treatment to encourage healing in infected limb wounds. Mortality from wound infection however, took a downward trend only when early wound excision was readopted and primary suture discarded in favour of delayed wound closure.

Although the 1939-45 War casualty rates were much lower than in the 1914-18 War, the standard of medical organisation and the use of professional talent far exceeded any in history: Wound excision and delayed primary suture had to be relearnt but infection and suffering were also greatly reduced by chemotherapy, antibiotics, the use of mobile field surgical and other specialised units, blood transfusion facilities, by advances in anaesthetics, and by casualty air evacuation.

After the second world war, there was an uneasy peace. In the Korean War, and in a succession of internal security operations followed by the Borneo confrontation, young army surgeons have obtained valuable experience of both wound and general surgery. Surgical equipment has continued to be revised and plastics have displaced rubber and 
glass items. Sterilisation standards have been improved and centralised. In this number Brigadier Wheatley's report on bullet wounds in Borneo is very instructive: gas gangrene did not occur but, in spite of antibiotics, less serious wound infections did, pointing to the need for attention to detail in surgical management. The value of blood transfusion in preoperative resuscitation and speedy convalescence of casualties has been firmly established and the quantities of blood used in Borneo more than doubled World War II figures. With banked blood only having a three week life, the stock piling of adequate quantities of blood for future major emergencies would be virtually impossible but for the promise of current work on a method of quick freezing of blood for indefinite storage.

What of the future of military surgery? Progress hitherto must not give way to complacency. Our fighting men will be handling and facing weapons of increasing complexity and destructive power, and the injuries to which they will be liable will continue to be wounds, fractures, blast and burns. Surgical care must continually strive to ensure that the soldier will not only survive but survive to fight again. While every development in science and surgery must be scrutinised for its possible practical application to surgery in the field, the sheet-anchor of battlefield surgery will continue to be early wound excision and delayed primary closure with antibiotics as an essential complement, to be given as soon after wounding as possible. The important question to be answered is how much longer than six hours can wound surgery be delayed, if necessary, under effective antibiotic cover? It is still too early confidently to modify the well tried policy of wound surgery within six hours, though it is encouraging to learn that in Brigadier Wheatley's experience of moderate bullet wounds in Borneo the delay could be as much as 36 hours under antibiotic cover. The experiments of Matheson and Thoresby reported in this issue suggest that in animals at least, penicillin alone seems, if given promptly, to ensure protection against gas gangrene contamination. Antibiotics alone may, of course, have to be relied upon when the numbers of casualties overwhelm surgical resources and involve a delay in surgery for many. In the management of mass casualties, MajorGeneral R. A. Stephen's article deserves careful study for natural disasters occur even more frequently than wars.

The future depends on the enthusiasm, training and experience of our young surgeons. If opportunities for field surgery dwindle, the surgical work in campaigns elsewhere such as in Vietnam, must be closely studied, and the lessons of the past must not be forgotten in the excitement of new developments.

\section{Royal Australasian College of Physicians}

Lieutenant-General Sir Robert Drew was amongst new Fellows elected at a meeting of the College's Body of Fellows on 13th October, 1966.

\section{Colonel Commandant, R.A.M.C.}

Major-General William Arthur Robinson, C.B., O.B.E., M.D., has been appointed in succession to Lieutenant-General Sir Alexander Drummond. 


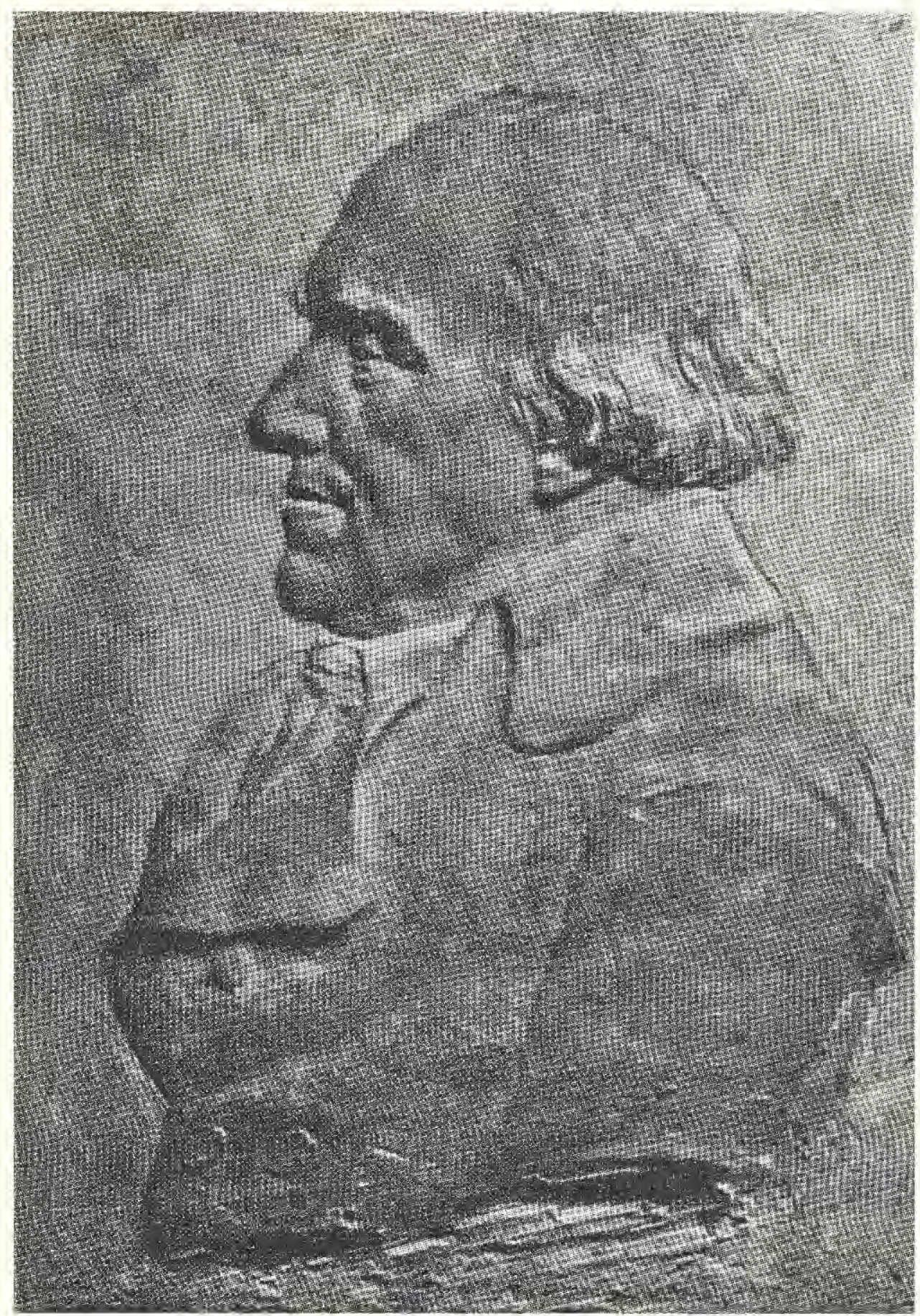

From the plaque by John Tweed (1869-1933) 